vol. 23 - n² | 2007

Numéro ouvert

\title{
Judith RAINHORN, Paris, New York: des migrants italiens - Années 1880 - années 1930
}

\section{Ralph Schor}

\section{(2) OpenEdition}

1 Journals

\section{Édition électronique}

URL : https://journals.openedition.org/remi/4193

DOI : $10.4000 /$ remi.4193

ISSN : $1777-5418$

Éditeur

Université de Poitiers

\section{Édition imprimée}

Date de publication : 1 octobre 2007

Pagination : 220-222

ISBN : 978-2-911627-46-6

ISSN : 0765-0752

\section{Référence électronique}

Ralph Schor, « Judith RAINHORN, Paris, New York: des migrants italiens - Années 1880 - années $1930 »$, Revue européenne des migrations internationales [En ligne], vol. 23 - n² | 2007, mis en ligne le 27 novembre 2008, consulté le 16 avril 2022. URL : http://journals.openedition.org/remi/4193; DOI : https://doi.org/10.4000/remi.4193

Ce document a été généré automatiquement le 16 avril 2022.

(c) Université de Poitiers 


\title{
Judith RAINHORN, Paris, New York: des migrants italiens - Années 1880 - années 1930
}

\author{
Ralph Schor
}

\section{RÉFÉRENCE}

Judith RAINHORN, Paris, New York : des migrants italiens - Années 1880 - années 1930, Paris, CNRS Éditions, CNRS Histoire, 2005, 233 pages. ISBN : 2-271-06330-2.

1 Empruntant le chemin fécond de l'histoire comparative, Judith Rainhorn a confronté les processus de migration et d'intégration des Italiens dans les deux quartiers populaires de la Villette à Paris et de East Harlem à New York, des années 1880 aux années 1930.

2 L'échelle démographique globale des deux grandes villes diffère : en 1914, la capitale française compte 46000 Italiens ; en 1920, New York, avec plus de 800000 Transalpins, est la deuxième ville italienne du monde après Rome. Dans les quartiers, l'arrivée des premiers immigrés est enregistrée au début des années 1880. À la Villette comme à East Harlem les nouveaux venus s'entassent dans des logements exigus et insalubres. Les déménagements, dus à la recherche des meilleures conditions d'habitat et de travail, apparaissent fréquents. Les Italiens et les autochtones, rivaux sur le marché de l'emploi, s'affrontent parfois durement. Aux États-Unis, les nativistes rejettent les Italiens catholiques comme les émigrants juifs, tous accusés d'envahir et de dénaturer l'Amérique.

3 Importante se révèle la dimension familiale de l'immigration. Rares sont les célibataires. À Harlem, le mariage endogamique, réunissant des couples de même origine régionale, est de règle. À la Villette où la population italienne compte plus d'hommes que de femmes, l'union mixte est plus fréquente. La première génération, peu qualifiée, occupe des emplois modestes, métiers ambulants, cireurs de chaussures, 
chiffonniers, balayeurs de rues, débardeurs au port de New York, égoutiers, gaziers, maçons... à Paris. Vers 1920, après quatre décennies d'immigration massive, $83 \%$ des Italiens de la Villette appartiennent encore au mode ouvrier et $6 \%$ au petit commerce et à l'artisanat. Un timide début d'ascension sociale se manifeste cependant au sein de la deuxième génération née en France avec un gonflement significatif des métiers ouvriers plus qualifiés de l'industrie mécanique et des emplois de bureau. À Harlem, les petits métiers se raréfient fortement vers 1920, tandis que se développe remarquablement le mode des employés et du petit commerce qui traduisent une mobilité socioprofessionnelle ascendante. Quant aux femmes, celles de la Villette entrent en nombre dans la vie professionnelle, surtout à la deuxième génération, pour devenir sténodactylographes, vendeuses, demoiselles des PTT, tandis qu'à Harlem, le poids du modèle familial importé d'Italie méridionale maintient plus souvent la femme au foyer.

4 En matière religieuse, l'encadrement clérical demeure faible. Cependant la pratique demeure, surtout pour les femmes et à l'occasion des grandes fêtes liturgiques ou des rites de passage. $\mathrm{Si}$, avec le temps, la ferveur tiédit nettement à Paris, elle reste plus vivace à New York, notamment grâce à un regroupement identitaire autour de la Madone du Mont carmel, dans une église bâtie par les Italiens dès le 8 décembre 1884 .

5 La sociabilité s'apprécie à travers la vie associative, faible à la Villette, très forte à Harlem où le regroupement constitue un facteur de survie de l'italianité. L'identité est également entretenue par les loisirs comme les jeux de cartes et de boules, mais l'attrait grandissant des jeunes pour le cinéma et le sport uniformise progressivement les goûts. Au point de vue politique, la grande majorité des Italiens affiche son indifférence. Cependant des engagements sont observés à la marge : anarchistes à la fin du XIX ${ }^{e}$ siècle, grévistes à la Villette dans des conflits localisés, antifascistes souvent originaires du nord de l'Italie et réfugiés en France, fascistes plutôt venus du sud. À Harlem, le mouvement mussolinien essaie de se donner une image respectable et connaît quelques succès, notamment dans la prise de contrôle des associations. L'antifascisme new yorkais se fortifie cependant au début des années 1930. Si l'identité italienne semble se déliter rapidement à Paris, elle se cristallise dans la grande ville américaine grâce à l'immense popularité du maire La Guardia, issu de l'immigration.

Après la grande Guerre, les nouvelles arrivées d'Italiens cessent à Harlem et se maintiennent à la Villette où elles remettent en cause l'intégration entreprise par les plus anciens. Dans les deux quartiers, la population italienne se dirige de plus en plus vers d'autres banlieues et est remplacée, dans les logements toujours aussi médiocres, à Paris par des Arméniens, des Grecs, des Juifs d'Europe centrale, à Harlem, par des noirs américains et des Portoricains qui se heurtent souvent aux Italiens encore sur place.

7 Les réactions loyales des Italiens à l'égard de leur deuxième patrie au début de la Seconde Guerre mondiale montrent la sédentarisation et l'intégration des immigrés. Le livre identifie bien les processus complexes d'identification progressive à un nouveau pays. La présence de la famille et la naissance d'enfants constituent de puissants obstacles au retour. Cependant l'immigration familiale forme en même temps un réseau qui, par la parenté, les relations et les pratiques quotidiennes, entretiennent les racines culturelles. Ces dernières survivent ou s'étiolent sous le coup d'autres facteurs : répression politique dans le pays d'origine, conjoncture économique dans le pays d'accueil, xénophobie manifestée ou non par celui-ci, influence des modèles, démographique, politique, culturel que l'immigré trouve dans sa nouvelle résidence. 
8 Ainsi ce livre ne renouvelle pas la connaissance des sociétés immigrées, mais par sa richesse, la précision des observations et la pertinence des exemples fournis, il fait mieux comprendre les évolutions et relativise les modèles d'intégration réputés spécifiquement américain et français. Sans doute des différences existent-elles. À Harlem, les Italiens semblent souvent s'enfermer dans une " forteresse assiégée », à la Villette au contraire ils se diluent discrètement, sans heurt apparent. Mais ces réalités contrastées semblent résulter moins d'une politique délibérée définie au sommet de l'État que de facteurs contingents comme l'origine régionale des Italiens, la composition des familles, l'influence plus ou moins grande des structures d'encadrement. Deux traditions d'intégration existent certainement, de part et d'autre de l'Atlantique, mais elles sont confrontées à des dynamiques immigrées différentes qui peuvent retarder ou accélérer le cours des évolutions socioculturelles.

\section{AUTEURS}

\section{RALPH SCHOR}

Université de Nice Sophia-Antipolisfr 